\title{
Integration, Disintegration, and Reintegration via Advanced Information Technology
}

\author{
CONRAD PHILLIP KOTTAK
}

University of Michigan

\begin{abstract}
American culture is shifting from a mass culture toward increasing specialization and diversification. The growth of communication in cyberspace is consistent with this trend inasmuch as it supports the proliferation of interest and affinity groups. Socioeconomic, demographic, and cultural factors affect access to, use of, and behavior within this communication space. Other forms of regulation of the use of cyberspace include the emerging norms of on-line discussion groups and political attempts to regulate the content of the Internet.
\end{abstract}

Keywords: Internet, mass media, group formation, publics

$\mathbf{O}$ ne key development in American culture since the 1960s, especially evident in the media, is a general shift from "massification" to "segmental appeal." An increasingly differentiated nation celebrates diversity and fosters affinity groups and identity politics. The mass media_-print and electronic_-join the trend, measuring various "demographics" and aiming their products and messages at particular segments rather than at an undifferentiated mass audience. Television, films, radio, music, magazines, and Internet newsgroups all gear their topics, formats, and styles toward particular homogeneous segments of the population (i.e., "interest groups" and target audiences). In particular, cable TV and the videocassette have helped direct television, the most important mass medium, away from the networks' cherished mass audiences toward particular viewing segments.

Mass culture lives on, however, in some of the "emerging markets." For example, with the second largest middle class in the Americas (50 million people), Brazil is now experiencing a period of mass consumption that in some ways recalls 1950 s America. And Brazilian television continues to illustrate massification. That nation's dominant network, Rede Globo, the most watched commercial television network in the world, regularly attracts nightly audiences of 80 million people to its popular telenovelas (Kottak, 1990). Those programs have true mass appeal, as did American programs of the 1950s and 1960s such as Ed Sullivan, I Love Lucy, and The Brady Bunch. With massification, almost everyone watches the same thing.

In North America, by contrast, special-interest audiences are proliferating as part of a general pattern of increasing specialization and diversification-a key feature of contemporary lives. ${ }^{1}$ High technology has the capacity to tear all of us apart even as it brings some of us together.

Cyberspace, a world navigable via computer, is part of a larger high-tech communications environment that may be called advanced information technology (AIT). A related term, 
used by Vice President Al Gore, is the National Information Infrastructure, or the NII, which is better called the GII because it is global in scope. Other elements of this environment include computer hardware and software, modems, advanced telephone systems, cable TV, satellite dishes, faxes, and even radio and television talk shows, all of which have both integrative and disintegrative functions.

Just as AIT cannot be understood apart from other changes going on in society, it should not be studied just nationally; one of its key features is its international scope. Along with modern transportation systems, AIT plays a key role in connecting people worldwide. It has challenged or is challenging the authoritarian governments of the Soviet Union, Iran, China, Vietnam, Singapore, Malaysia, and Indonesia. AIT undermines authoritarian states by allowing the expression of diverse opinions including dissident voices.

A developing interdisciplinary field known as science and technology studies recognizes that science and technology are crucial arenas for creating culture and sociality in today's world (Escobar, 1994). AIT connects people in both wider and narrower networks. Many of us subscribe to specialized newsgroups, services, and bulletin board services (BBSs). A particular newsgroup unites people from all over the world who share a common interest. Yet the Internet and related environments also encourage, maintain, reinforce, and strengthen differences.

Some of the groups linked by AIT are transnational. Fax machines and e-mail promote the almost instantaneous global diffusion of fairly complex documents. The thousands of newsgroups on Usenet are read internationally by people with common interests. Some newsgroups focus on health issues (e.g., alt. support. tinnitus) or politics. Others focus on nations (e.g., the soc. cul ture groups such as soc.cul ture. brazil and soc.culture.singapore). They provide a common forum for scholars and others interested in a particular nation or for its citizens in various locales. Some newsgroups are support groups for people with common maladies, experiences, or identities. Some are commercial and allow the posting of ads. Proper "netiquette," the evolving set of rules for Internet communication, makes it obligatory to distinguish between the commercial and noncommercial forums. Those who post improperly, whether deliberately or unwittingly, subject themselves to a prime Internet sanction - the "flame," a series of angry messages from offended group members all over the world. Some of the narrow focus groups are very esoteric indeed (e.g., alt. sex. bestiality.hamster. duct-tape).

Narrow focus groups may be based on work cultures and other affinity groupshomogeneous groups of user-participants (Harvey, this issue). They may link members of a single organization in one place, branches of that organization in different places, or similar professionals (e.g., ear, nose, and throat physicians) all over the world.

Transecting groups create direct communication channels between groups that previously had, or otherwise have, trouble communicating (e.g., physicians and patients). Transecting groups include health-oriented support groups on the Internet to which physicians, sufferers, and other "experts" contribute regularly. Other forums focusing on health conditions are available on-line at various sites including the World Wide Web and live real-time forums.

Although AIT links the world, access to its riches is unequal both among and within nations. The less developed countries (LDCs) have poorer access than do Japan, Western Europe, North America, and Australia/New Zealand. Poverty and technological underdevelopment are key factors limiting access in Africa and many parts of Latin America and Oceania. In Asia, authoritarian governments attempt to devise means of limiting their citizens' access even as they recognize the economic benefits of connectivity (e.g., instant access to financial information). China, for example, has priced cyberspace connectivity beyond the reach of ordinary people. 
Even within a developed nation such as the United States, socioeconomic, demographic, and cultural factors affect access to and use of cyberspace. Not everyone has been or will be integrated equally. There is privileged access to AIT by class, race, ethnicity, gender, education, profession, age, and family background. Young people tend to be more comfortable with AIT than do old people. Kids who grow up with computers in their homes become familiar with them and are more likely to use them than are offspring in computerless homes.

Class affects both access to and use of AIT. Families with higher incomes and greater wealth tend to have better access to the range of high-tech items. Members of such families also tend to have and get better educations and to participate in the information-processing settings and professions in which AIT is used most regularly. There is some evidence that communication via cyberspace can break down barriers between differentially privileged members of a physical community (town or city). Michaelson (this issue) describes communication networks linking homeless people using public library computers and middle-class people using computers in homes, jobs, and schools and similar connectivity between children and the elderly. These communication networks would not have been established without computers.

Still, communication via AIT has not banished class bias despite several democratizing features of cyberspace communication. Class-based contrasts are reduced but not eliminated. One equalizing feature of cyberspeak (the range of styles and conventions people use when they write messages in cyberspace) is its informality compared to print. Specific communicative and linguistic practices develop in different media. Language is neither as fixed nor as precise as it is in writing for print. Cyberwriters are not as concerned with typos as are writers for print. Writing exclusively in capital letters (using the Caps Lock key) is bad form ("shouting"). Lower case letters are proper, and some people use capital letters hardly at all. Others are more attentive to the canons of print. Along with vocabulary and punctuation, this is a way in which training and education show up. Class anonymity is not fully possible, nor, probably, is gender. Using expletives or beginning a message with the salutation "Dude" suggests male identity. And female use of cyberspace sometimes shows some of the sociolinguistic insecurity that has been noted in other contexts (Lakoff, 1975; Tannen, 1990). From postings I have read, I suspect that women are more likely to end their messages with disclaimers, such as "but that's just my opinion," whereas men choose the more emphatic "IMHO" (in my humble opinion) to express the same sentiment.

Groups with more restricted access to AIT include minorities, the poor, females, old people, and LDCs. There is some indication that cultural factors affect minority use of AIT; for example, African Americans may view the computing environment as a "White thing." People with different cultural backgrounds will interpret and use technological artifacts in different ways, but socioeconomic factors also play an important role. Despite the American ideology of equality and the self-identification of most Americans with the middle class, many disturbing and lingering aspects of our culture are based on socioeconomic stratification.

From case studies of economic development in the LDCs_Java's "Green" Revolution, for example-we know that an initial uneven distribution of resources often becomes the basis for greater inequality as a technological shift progresses. This lesson has an American application. If current class-based trends in access to technology continue, we face results such as Java's. The United States has a "persistent and substantial inequality in the access to new technology among both schools and school children... . The poorer a school is, the less likely that school is to have any of this new technology."2 Math, science, the computer, and information processing are the strategic resources of a high-tech society, just as dams and irrigation canals are for Java's rice farmers. Microcomputers and associated AIT are concentrated in affluent school districts. Unless our schools provide widespread access to 
AIT equipment and training, continuation of the current distribution pattern, based on income and differential tax support, will ensure that we raise a differentially privileged generation of computer whizzes and dolts, the children of richer and poorer Americans.

If access does not start at home, it may begin in a public setting such as a school or library. But in the United States, school and library funding varies markedly among regions, states, cities, towns, and neighborhoods. Access to cyberspace requires not only computers and software but wiring of classrooms and payment of phone charges for connectivity to wider systems. Many schools have computers, but they still lack proper software and the physical means of connecting to the wider, information-rich resources of the Internet, the World Wide Web, and gopherspace.

In addition to communication-style differences based on class, elitism affects cyberspace in other ways. All liberating technologies face attempts by elites to seize control, proposals to guide that medium toward prosocial goals (social engineering), and claims to know better than do ordinary people how the system should be used. We may generalize that elites, censors, and others who think they know best will attempt to regulate or control any potentially democratizing medium-from television to cyberspace. David Hess, in this workshop on "Culture, Society, and Advanced Information Technology," noted the history of early and primary use of cyberspace and AIT by the American defense establishment, academics, and corporations. Escobar (1994) speculates that military- and profit-oriented applications will continue to dominate in cyberspace.

One of the most flagrant manifestations of elitism occurred as 2 million members of America Online ("AOLers") joined the Internet a few years ago. Traditional users lambasted the novices for their ignorance of proper netiquette. AOLers have not yet managed to shake their stigmatized status as second-class citizens of cyberspace. There is even a newsgroup titled alt. aol-sucks.

Notice the interplay of class, education, and gender stereotypes in one AOLer's response to the university community.

Who gives a rat's ass what a bunch of beady eyed, bespectacled, nerdy engineering students with net names like pimple@assholenet.com, typing with one hand and jerking off with the other as they post pictures of girls they wish would even let them sniff the chair they sit on think. AOL's here to stay, Jack, and there isn't one fucking thing you can do about it. So why don't you move on. By the way, I love the way you snobs accessing via university computers engage in generalization about large groups of people. Usually the mark of a first semester freshman encountering the real world for the first time.

Social scientists are studying ways in which AIT is fostering new social constructions of reality and computers are changing notions of identity and the self. Virtual worlds (e.g., anonymous computer role-playing games, or MUDs [multiple user dimensions]) are ways of extending various selves into forms of cybersocial interactions (Escobar, 1994). People make statements about and manipulate their identities when they choose various "handles," their names in cyberspace. If one engages in on-line communication through multiple channels (e.g., a university gateway, a commercial service, and a BBS), one may have various handles and identities. One must then keep track of the identities he or she uses for different accounts. In some contexts, people manipulate (i.e., lie about) their ages and genders and create their own cyberfantasies.

Even as they challenge elitism and traditional authority, democratizing media still have barriers and gatekeepers. It takes special knowledge, background, and flexibility to hook up with the various communication modes available via AIT and with constantly changing systems. The elderly are at a disadvantage, al though retirees have the time to use cyberspace 
productively. Old people even have trouble using the array of information-extraction opportunities available via the touch-tone phone. Use of an automatic teller machine can be frightening for people with low-tech abilities or poor eyesight. Still, cyberspace eventually could prove to be a social boon for the elderly, who, like other segments of the North American population, are more socially isolated from their families now than they were 30 years ago.

Cyberspace is regulated, then, by people's backgrounds and demographic characteristics. Also, users regulate one another-through direct statements, flames, and other devices (e.g., "kill" or "squelch" commands that snip particular links)—when someone is seen as abusing the canons of a specific group or of cyberspace generally.

There are more formal gatekeepers too. Exhibiting a Singapore-like distrust of open information including pornography-especially its availability to children-a 1995 U.S. Senate bill promoting "communications decency" aimed to expand government regulation of cyberspace. Other bills would increase regulation to fight crime or terrorism. Many cyberspace forums are already "moderated," and all systems have "sysops" (systems operators) who play some kind of regulatory role in terms of access, if not in terms of what is said on-line. Still, many real-time on-line forums permit instantaneous, free-for-all, unmoderated conversation. These are much more democratic than, say, radio talk shows, for which gatekeepers screen callers.

Guiding this discussion so far has been the implicit assumption that people use AIT for their own ends - for purposes that make sense to them in the context of their everyday lives, to make those lives a little easier or more interesting. Sometimes, however, use of AIT is imposed. Superiors (e.g., company management) may force subordinates to use AIT and then follow that use closely, perhaps to monitor work performance.

Social scientists are still investigating how the use of cyberspace is related to the use of other media and to participation in face-to-face groups and communities. One unresolved question is how participation in an on-line forum affects participation in face-to-face groups based on the same issue (e.g., alcohol abuse). There is no a priori reason to assume that one form of participation will diminish the other. For example, my research in Brazil revealed television's role in promoting a general "media hunger"- the more people watched television, the more they were likely to use all available media. The number of media-hungry people and information addicts is increasing worldwide. Such people surely will be attracted to cyberspace. And the growth of real-life support groups has been correlated with their appearance in various media (print, radio, television, and cyberspace).

I do not see that AIT plays an especially novel or important role in promoting the decline of face-to-face communities, which have been declining for other reasons for many years. Long ago, social scientists linked this phenomenon to urbanization. For example, in several books, Redfield (1941) attempted to identify the main contrasts between rural and urban life. He contrasted rural communities, whose social relations are on a face-to-face basis, with cities, where impersonality characterizes many aspects of life.

In many ways, cyberspace replicates New York City. People sleep in different apartments and have little to do with their neighbors. They get up and go to work, where they interact with their coworkers. They get together with family, friends, and people who share their interests-in varied settings.

Social scientists disagree about the effects of cyberspace-based (virtual) communities on face-to-face social life. Despite certain, rather utopian, visions of the role of virtual networks in integrating physical communities (as discussed by Kling and others in this issue), I doubt that AIT will play much of a role in strengthening whole local communities--towns and cities. Rather, I predict that AIT will be used mainly to facilitate communication among 
affinity groups-relatives, friends, and people with common identities, experiences, or interests (especially work interests). AIT will be used especially for immediate communication within groups of coworkers and members of common organizations. Its main role, however, will be to establish and maintain links between physically dispersed people who have, and come to have, more in common.

\section{NOTES}

1. We also see this trend toward segmentation in department stores. Floors of major urban department stores now imitate the separate stores of malls by having individual boutiques (e.g., Liz Claiborne, Calvin Klein). This trend, which may have been started by Bloomingdale's, has spread in New York City and throughout the country. The process is one of boutiquizing America.

2. Testimony of Linda Tarr-Whelan of the National Education Association to the House Committee on Science, Research and Technology, as quoted in Grassmuck (1985, p. A11).

\section{REFERENCES}

Escobar, A. (1994). Welcome to Cyberia: Notes on the anthropology of cyberculture. Current Anthropology, 35(3), 211-231.

Grassmuck, K. (1985, February 10). Local educators join push for "a computer in every classroom." Ann Arbor News, p. A11.

Kottak, C. P. (1990). Prime-time society: An anthropological analysis of television and culture. Belmont, CA: Wadsworth.

Lakoff, R. (1975). Language and woman's place. New York: Harper \& Row.

Redfield, R. (1941). The folk culture of Yucatan. Chicago: University of Chicago Press.

Tannen, D. (1990). You just don't understand: Women and men in conversation. New York: Ballantine.

Conrad Phillip Kottak is a professor of anthropology at the University of Michigan, where he has taught since 1968. His interests are in processes by which smaller systems (including local communities and regions) are drawn into larger systems. 